\title{
Educação infantil no campo e os avanços no aspecto legal: reconhecimento da educação como direito social para as crianças camponesas
}

\author{
Edna Souza Moreira ${ }^{1}$, Geângelo de Matos Rosa ${ }^{2}$, Isaura Francisco de Oliveira ${ }^{3}$ \\ ${ }^{1}$ Universidade do Estado da Bahia - UNEB. Departamento de Ciências e Tecnologias. Campus XVII. Rua Joana \\ Angélica 326, Bairro São João. Bom Jesus da Lapa - BA. Brasil. esmoreira@uneb.br. ${ }^{2}$ Instituto Federal de \\ Educação, Ciências e Tecnologia Baiano - IFBAIANO. ${ }^{3}$ Universidade do Estado da Bahia - UNEB.
}

\begin{abstract}
RESUMO. O ano de 1998 foi um marco na história da educação do campo com a realização da Primeira Conferência Nacional Por uma Educação do Campo que articulou diversos segmentos da sociedade, dentre eles, movimentos sociais e universidades em defesa da construção de uma proposta de educação que contemple as especificidades do modo de vida no campo. Desse modo, esse artigo surge a partir da seguinte questão: como o aporte jurídico que orienta a educação tem contemplado as questões inerentes à educação infantil do campo, sobretudo a partir de 1998? Para tanto, realizou-se uma pesquisa de cunho bibliográfico analisando leis e diretrizes da educação com vistas a compreender o processo de constituição da educação infantil no campo a partir do aparato jurídico que orienta a organização desta etapa da educação básica. As considerações aqui tecidas podem servir de subsídios na reflexão sobre as políticas de educação do campo, em particular, as que asseguram o desenvolvimento da educação infantil, uma vez que foi possível concluir que a educação do campo, em particular a primeira etapa da educação básica, já se faz significativamente presente nas leis e diretrizes, no entanto, ainda existem grandes lacunas para serem superadas a fim de que as crianças sejam plenamente reconhecidas como sujeitos de direitos.
\end{abstract}

Palavras-chave: Educação Infantil do Campo, Legislação, Sujeito de Direito. 


\title{
Early childhood in the rural education: recognition of education as a social right for peasant
}

\begin{abstract}
The year 1998 was a milestone in the field of education of history with the holding of the First National Conference Towards a Rural Education which articulated various segments of society, including social movements and universities in support of the construction of an educational proposal that includes the specifics of the way of life in the field. Thus this article arises from the following question: how the legal contribution that guides education has covered the issues related to early childhood education field, especially from 1998. Therefore, it held one bibliographic nature of research analyzing laws and education guidelines in order to understand the process of formation of early childhood education in the field from the legal apparatus that guides the organization of basic education stage. The considerations here woven may provide support in the debate on rural education policies, in particular, to ensure the development of early childhood education, as it was possible to conclude that the education field, in particular the first stage of basic education since it is significantly present in the laws and guidelines, however, there are still large gaps to be overcome so that children are fully recognized as subjects of rights.
\end{abstract}

Keywords: Early Childhood in the Rural Education, Legislation, Right of Subject. 


\section{Educación infantil en el campo: el reconocimiento de la educación como un derecho social para los niños campesinos}

RESUMEN. El año 1998 fue un hito en el campo de la enseñanza de la historia con la celebración de la Primera Conferencia Nacional Hacia una Educación Rural que articula diversos segmentos de la sociedad, incluidos los movimientos sociales y universidades en apoyo de la construcción de una propuesta educativa que incluye los detalles de la forma de vida en el campo. Así surge este artículo de la siguiente pregunta: ¿cómo la contribución legal que guía la educación han cubierto las cuestiones relacionadas con el campo de la educación de la primera infancia, especialmente a partir de 1998. Por lo tanto, se llevó a cabo una sola naturaleza bibliográfica de las leyes de análisis y de investigación directrices para la educación con el fin de comprender el proceso de formación de educación infantil en el campo del aparato legal que guía a la organización de la etapa de educación básica. Las consideraciones aquí tejidas pueden proporcionar apoyo en el debate sobre las políticas de educación rural, en particular, para garantizar el desarrollo de la educación infantil, ya que era posible concluir que el campo de la educación, en particular la primera etapa de la educación básica ya que es significativamente presente en las leyes y directrices, sin embargo, todavía hay grandes lagunas que hay que superar para que los niños sean plenamente reconocidos como sujetos de derechos.

Palabras-clave: Educación Infantil en la Educación Rural, Legislación, Sujeto de Derecho. 


\section{Introdução}

Assim como o campo, a Educação Infantil no Brasil tem sua trajetória marcada por negação, estereótipos e, consequentemente, desvalorização. $\mathrm{O}$ campo brasileiro apesar de, por muito tempo, ter sido a principal fonte de divisas em nosso país, particularmente através da agricultura, ao longo da história esse espaço foi considerado local de atraso. No Brasil, cultivava-se a ideia de que as pessoas moradoras do campo também eram "atrasadas" e que, por lidarem com o serviço da lavoura que não demanda instrução acadêmica, não era necessário investir em educação, bastava ofertar apenas os rudimentos da leitura, da escrita e da matemática. A educação infantil sequer era mencionada, talvez porque seu surgimento esteja atrelado ao processo de urbanização e da industrialização. Nesse sentido, Silva, Pasuch e Silva destacam que

Em relação ao campo, a concepção de que sua população rural não precisa de creche/pré-escola, por vezes, está fundamentada em imagens saudosistas, nostálgicas e romantizada sobre o espaço rural ... Essa concepção serve para fortalecer a imagem de que o campo não existe mais como lugar de vida ... (Silva, Pasuch \& Silva, 2012, p. 45-46).

As autoras Silva, Pasuch e Silva (2012) ressaltam que a ausência do reconhecimento do direito à educação para as crianças de 0 a 05 anos está relacionada à concepção de que o campo sempre foi considerado como espaço de produção econômica que utilizava procedimentos simples, de maneira que os trabalhadores não precisavam de estudos para serem capazes de lidar com a produção agrícola.

Conforme dados do IBGE (2010), até 1960 a população que residia no meio rural era maior que a população que residia no meio urbano. Logo, o número de crianças no meio rural também era mais expressivo. Entretanto, esse cenário não era visto como motivo forte o suficiente para pressionar o Estado a inserir a educação para os sujeitos do campo na agenda política da época, haja vista que não havia sequer reconhecimento constitucional desse direito até a Carta Magna de 1988.

A partir do momento em que a Constituição assegura o direito à Educação Infantil, que a Lei de Diretrizes e Bases da Educação Nacional - LDB Lei 9394 de 1996 reconhece, no artigo 28, a especificidade metodológica da educação para os povos do campo e que a Resolução MEC/CNE/CEB n ${ }^{\circ} 05$ de 17 de dezembro de 2009 fixa as Diretrizes Curriculares Nacionais para a Educação Infantil contemplando as especificidades das crianças camponesas, surge a possibilidade de elaborar propostas que oportunizem a 
construção da identidade da escola do campo a partir da articulação entre os saberes científicos e tecnológicos, respeitando os tempos necessários à aprendizagem dos estudantes e os ciclos da produção agrícola.

Os trabalhos de pesquisa sobre a Educação Infantil do campo ampliaram significativamente nos últimos dez anos, porém, apesar desse crescimento, ainda existem muitas questões referentes a esta etapa da educação básica destinada às crianças de 0 a 05 anos que residem no campo que precisam ser estudadas. $\mathrm{O}$ presente artigo tem o desejo de contribuir com os estudos nessa área e, para tanto, o texto traz a seguinte estrutura: no primeiro momento, traçamos o percurso histórico da educação infantil no contexto do campo. Em seguida, analisamos a efetivação da Educação Infantil no campo como direito social fundamental considerando os avanços e as perspectivas a partir de 1988 e, por fim, apresentamos as considerações advindas do estudo.

Em síntese, esse artigo objetiva apresentar algumas reflexões sobre $\mathrm{o}$ percurso histórico do campo e da educação infantil do campo, articulando-as com os marcos que foram considerados avanços ou retrocessos nesse percurso.

\section{Educação infantil no contexto do campo: breve percurso histórico}

No Brasil, o campo sempre foi um lugar do paradoxo, pois ao mesmo tempo em que é o lugar do agronegócio, é também o espaço da agricultura familiar; é o lugar da produção econômica, mas é também o local da produção de arte, de saberes e de cultura. É um espaço que durante vários anos foi considerado local do atraso, ao mesmo tempo, que era a principal fonte de divisas.

O campo carrega as marcas dos estereótipos, a submissão ao meio urbano, pois é neste último que está concentrada a presença de instituições públicas e privadas como agências bancárias, escolas, hospitais e luz elétrica, dentre outras. No meio rural a vida sempre foi considerada difícil, o trabalho com a lavoura de sol a sol somada à concorrência, em condições desiguais, com o agronegócio transforma o campo num espaço quase inóspito para aqueles que não conhecem a sua dinâmica.

Após muitos enfrentamentos entre o Estado e os sujeitos organizados do campo, particularmente os movimentos sociais ligados à luta pela terra, engajados na reivindicação por condições de vida digna no campo, os termos campo e camponês passaram a ser utilizados enquanto constructos que buscavam superar as marcas de negações que estavam atreladas à palavra rural e, por extensão, ao homem trabalhador rural. 
Para Cavalcante (2010, p. 557) "o termo 'campo' é resultado de uma nomenclatura proclamada pelos movimentos sociais, adotada pelas instâncias governamentais e suas políticas públicas educacionais mesmo quando ainda relutantemente pronunciada em alguns universos acadêmicos dos estudos do 'rural'".

No que se refere ao público infantil, no Brasil as primeiras ações voltadas para atender as demandas da infância eram de cunho assistencialista e não preocupavam com a educação desses sujeitos. Eram medidas ora de cunho religioso, como por exemplo, a roda dos expostos, as casas de misericórdia entre outras, ora médico higienista ou jurídico policial, essas duas últimas com vistas a combater a mortalidade infantil.

As primeiras ações com a finalidade de educar crianças de 0 a 07 anos de idade datam do ano de 1875, como destacam Kuhlmann Jr. (2000) e Andrade (2010) com a criação dos jardins de infância, os quais atendiam crianças de 04 a 06 anos, ou seja, tinham a finalidade de educar. Com o desenvolvimento industrial e a crescente demanda por mão de obra, o que estimulou a inserção da mulher no mercado de trabalho e provocou, em 1921, a construção de creches para receber e cuidar das crianças, enquanto os pais estão fora de casa trabalhando. Antes da construção das creches, outras medidas já haviam sido tomadas para atender as crianças que de algum modo eram indesejadas, como: a roda dos expostos, além dos asilos, casas de misericórdia e maternais, para atender as crianças enquanto as mães trabalhavam, além de ajudar com a educação higiênica da própria família, contribuindo para diminuir a mortalidade infantil. Essas iniciativas apoiavam-se na concepção médico higienista de cunho assistencialista.

Esse cenário nos conduziu a duas considerações importantes: Primeiro, a educação infantil tinha iniciativas voltadas para crianças de família mais abastadas, e que no caso eram os jardins de infância os quais eram mantidos pela iniciativa privada, passando a ser contemplados pelo setor público a partir de 1896; e as creches voltadas para cuidar e higienizar os filhos das mães operárias; Segundo, havia nítida separação entre cuidar e educar, de maneira que as instituições para atender crianças abandonadas ou de famílias pobres estavam voltadas para o cuidar e higienizar as crianças de 0 a 04 anos e os jardins de infância, que atendiam as crianças com 05 e 06 anos - filhas de famílias burguesas, dedicavam-se a educar as crianças. 
A concepção de cuidado e de educação/instrução desenvolvida nas instituições anteriormente mencionadas passou por várias mudanças e ressignificações, bem como os profissionais que trabalham nessas instituições. A educação infantil no Brasil, de modo particular a creche passa a fazer parte das agendas de governo a partir do desenvolvimento industrial. As leis trabalhistas de 1943 previam a construção de creches pelas empresas próximas ao local de trabalho.

A clivagem entre as concepções de cuidar e educar e entre creches e jardins de infâncias perduraram do final do século XIX, quando criam as primeiras instituições dessa natureza. De 1900 até 1988 ampliou-se o número dessas instituições de maneira significativa, porém, estava longe de atender a demanda de todas as crianças com idade de 0 a 6 anos. Em pleno século XXI, ainda estamos longe de atender universalmente esta demanda.

As constituições de 1824 e 1891 nada sinalizaram sobre as demandas da infância. A primeira Constituição a registrar alguma preocupação com as crianças menores de 07 anos foi promulgada em 1934 e traz:

Art. 138. Incube a União, aos estados e municípios nos termos das leis respectivas: b) estimular a educação eugênica;

c) amparar a maternidade e a infância;

Art. 141. É obrigatório em todo território nacional, o amparo à maternidade e à infância, para o que a União, os estados e municípios destinarão $1 \%$ das respectivas rendas tributárias (Brasil, 1934).

Esta constituição, embora goze do status de ser a primeira a mencionar a obrigatoriedade do cuidado com a infância e de ser fruto da influência dos pioneiros da Escola Nova, ela silencia no que tange à educação das crianças com até 06 anos. Reconhece como obrigatório e assegura que será mantido pela iniciativa pública apenas o ensino primário, como destaca o artigo 150, parágrafo único, alínea a.

A Constituição de 1937, publicada durante a Ditadura do Estado Novo trata da infância, especialmente no artigo 127, onde discute que o Estado tomará as medidas necessárias para cuidar da infância e da juventude, inclusive assegurando o desenvolvimento intelectual, acrescenta no artigo 129 que é dever dos entes federados criar escolas para atender à infância e a juventude desprovida de capital financeiro. Embora essa Constituição destaque que os entes federativos devem assegurar $\mathrm{o}$ desenvolvimento intelectual da infância e da juventude, não assegura recursos financeiros e não diz nada sobre a educação das crianças menores de sete 
anos, além de não definir qual a idade que compreende como infância.

A Carta Magna de 1946, já em período de redemocratização, retoma no artigo 164 os dizeres da carta de 1934 e não faz referência à prática de eugenia. É a Lei de Diretrizes e Bases da EducaçãoLDB $\mathrm{n}^{\circ}$ 4.024, de 1961, que pela primeira vez trata claramente da educação destinada às crianças menores de sete anos nos artigos 23 e 24, porém traz como ensino obrigatório apenas o primário.

Logo, em 1964 acaba o curto período democrático e se instaura a Ditadura Militar que perdurou até 1985. Em 1967 é publicada uma nova Constituição Federal, que apesar do singelo avanço no que se refere à educação infantil que a primeira LDB já havia registrado, silencia sobre a educação das crianças menores de 07 anos e retoma no artigo $167, \S 4$, os dizeres da constituição anterior, ou seja, "A lei instituirá a assistência à maternidade, à infầncia e à adolescência”. (Brasil, 1967).

Em 1971, uma nova LDB é instituída através da Lei $n^{\circ} 5692$, de 11 de agosto de 1971. Aliás, esta lei ficou conhecida como a lei do ensino de $1^{\circ}$ e $2^{\circ}$ graus, pois tratava da reforma apenas desses níveis. Essa LDB, no capítulo II, quando trata do ensino de $1^{\circ}$ grau, destaca no artigo 19 a idade mínima de sete anos para frequentar o ensino primário obrigatório e apenas menciona no $\S 2^{\circ}$ que os sistemas de ensino deem um jeito para atender as crianças menores de sete anos através dos jardins de infância, em escolas maternais ou equivalentes.

A análise realizada acerca da história da educação infantil no Brasil evidencia um cenário de descaso. Pensar a educação infantil exige considerar o conceito de infância que o homem construiu ao longo da história e este conceito nos leva à criança do campo. Até o ano de 1988, quando promulgada a atual Constituição Federal, não havia registros sobre educação infantil para as crianças do campo. Ou seja, se o cenário da educação infantil até agora não parece muito alentador, ele fica mais crítico quando tratamos dessa etapa da educação básica no meio rural. Nesse espaço, quando muito, existia uma classe multisseriada, que atendia estudantes de diversas idades e séries/anos em um mesmo espaço e por um único professor.

Somente em 1996, com a Lei de Diretrizes e Base da Educação NacionalLDBN n 9394/96, é que a Educação Infantil passou a incorporar a Educação Básica e, ao ser reconhecida assim, "a educação passou a ser vista como o oposto da assistência. Olhávamos para o cotidiano das creches e ali víamos - como ainda hoje podemos ver em muitas delas - que elas 
funcionavam como depósito de crianças". (Kuhlmann Jr, 2000, p. 198).

Apesar da Lei $n^{\circ}$ 9394/96, a oferta de educação infantil no campo é recente, especialmente se pensarmos esse atendimento em creches e pré-escolas, já que são poucas as comunidades que possuem unidades de educação infantil. Essa situação contribuiu para que o direito à educação seja negado a um número expressivo de crianças com até cinco anos de idade. Apesar de algumas atitudes terem sido tomadas para assegurar essa etapa da educação para as crianças camponesas, estas eram medidas paliativas e compensatórias, referenciadas nos elementos da produção de vida urbana. A sociedade tem vivenciado um movimento para ressignificar a educação infantil do campo, de maneira que ela possa “... constituir um campo de ações políticas, práticas e conhecimentos em construção, procurando demarcar-se de um passado antidemocrático”. (Barbosa, et al., 2012, p. $15)$.

O descaso com a educação infantil do campo está atrelado ao estereótipo que acompanha esse espaço. Por muito tempo, os políticos disseram que para lidar com a terra e a enxada não era preciso ter muita instrução, como mostra o discurso proferido em 1926 pelo governador mineiro Melo Viana, citado em um texto do professor Miguel Arroyo:

\begin{abstract}
para um grande número de crianças, especialmente nas populações rurais, tem o ensino primário a finalidade exclusiva de alfabetização. A estas populações entregues aos trabalhos dos campos, à lavoura e à criação, a outros misteres onde não é exigida grande cultura intelectual, basta-lhes que saibam ler, escrever e contar. (Mensagem ao Congresso mineiro, 1926, p. 73 apud Arroyo, 1982, p. 02).
\end{abstract}

A Constituição Federal de 1988, elaborada em um contexto marcado por uma forte presença dos movimentos sociais e sindicais, inclusive aqueles ligados à posse da terra e o movimento por creches, dentre outros, traz um avanço significativo, qual seja: o reconhecimento da educação como direito de todos e que esta deve ser mantida pelos entes federativos em nível de ensino fundamental. Outro avanço significativo está relacionado à educação infantil, onde a referida Carta Magna no artigo 208, inciso IV, afirma que essa etapa da educação básica será assegurada pelo Estado através do "atendimento em creche e pré-escola às crianças de zero a seis ${ }^{\mathrm{i}}$ anos de idade”. (Brasil, 1988). Entretanto, ela não traz como obrigatória a oferta e a frequência na educação infantil; essa obrigatoriedade era só para o ensino fundamental. Somente com a Lei ${ }^{\circ} 12796$, de 04 de abril de 2013, essa 
obrigatoriedade foi estendida dos 04 aos 17 anos.

No que se refere à educação do campo ou educação infantil no campo, a Carta magna de 1988 nada traz, mas o fato de assegurar que a educação e o atendimento à infância é um direito social abriu um leque de possibilidades, somamse ainda os demais aparatos jurídicos posteriormente sancionados como, por exemplo, a LDB n 9394 de 1996, que pela primeira vez insere a educação infantil como a primeira etapa da educação básica.

De 1996 até os dias atuais esse aparato legal e normativo cresceu significativamente. Foram publicados: o Referencial Curricular Nacional para a Educação Infantil - RECNEI, as Diretrizes Curriculares Nacionais para Educação Infantil - DCNEI, a Lei n ${ }^{\circ} 11494$ de 20 de junho de 2007, que regulamenta o Fundo de Manutenção e Desenvolvimento da Educação Básica e de Valorização dos Profissionais da Educação-FUNDEB. Foi publicada, também, a Resolução $\mathrm{n}^{\circ} 01$ CNE/CEB, de abril de 2002, que instituiu as diretrizes operacionais para a educação básica das escolas do campo, a Resolução $\mathrm{n}^{\mathrm{o}} 02 \mathrm{CNE} / \mathrm{CEB}$ de abril de 2008 que institui as diretrizes complementares e o Decreto 7352, de 04 de novembro de 2010. Esse conjunto de referencial contribuiu, significativamente, para a elaboração da proposta de educação infantil para o campo e obrigou o Estado a reconhecer formalmente esta etapa da Educação Básica como direito social fundamental para as crianças camponesas, mesmo que na prática muito ainda precisa ser feito para que as crianças tenham acesso de fato a esse direito. Esses documentos serão objeto de reflexão mais adiante.

Com a Constituição Federal de 1988 inicia-se um processo de superação da clivagem entre educar e cuidar e, a partir de então, as crianças passam a ser consideradas sujeitos de direito que precisam ser cuidadas e educadas no seio das famílias e instituições escolares, como as creches e pré-escolas.

\section{Educação infantil no campo como direito social fundamental: avanços e perspectivas a partir de 1988}

Para facilitar a reflexão, é preciso esclarecer que a compreensão aqui adotada sobre o que é um direito social fundamental é apresentada por Bobbio (2004) e Comparato (2010). Esses autores destacam que após a Declaração Universal dos Direitos dos Homens publicada em 1948, que traz a educação como direito humano social fundamental, todas as nações, sobretudo as ocidentais, passaram a incorporar essa categoria de direitos. Porém, estes muitas vezes permanecem como letra morta, já que direitos dessa 
natureza são difíceis de serem fiscalizados pelos órgãos internacionais.

A Constituição Federal publicada em 1988, construída durante o processo de redemocratização resultante da intensa participação dos movimentos sociais e sindicais, traz a educação, a saúde, dentre outros, como direito social fundamental. De acordo com Bobbio (2004), um direito é social quando busca ampliar a ação do Estado junto à população e sendo fundamental, prescinde de investimento em direitos suplementares, essenciais à sua concretização.

Nesse sentido, a educação infantil constitui um direito social fundamental para as crianças camponesas de 0 a 05 anos, pois constitui uma condição para que elas possam acessar os saberes curriculares acumulados pela sociedade, além de adquirir as habilidades necessárias para continuar a busca por conhecimento. Para tanto, necessita de investimento como a construção de unidades de educação infantil, alimentação escolar, profissionais com a devida qualificação, os quais constituem direitos suplementares.

Pensar a educação infantil no campo significa provocar tensionamentos com o governo, com os professores e com a equipe gestora, pois esta proposta está ancorada na concepção de campo que hoje é veiculada nos meios acadêmicos e nos segmentos sociais de luta pela terra, onde destaca esse espaço como território conforme propõe Fernandes (2006), ou seja, um lugar de produção de cultura, de saberes e de economia, em contraposição à ideia de rural, o qual era visto como local do atraso, numa visão pessimista ou como local de lazer, numa concepção saudosista.

A educação infantil do campo ainda é uma proposta em construção e propõe romper com a lógica da educação rural que apresenta o campo como submisso ao urbano. Não é o resíduo da educação infantil urbana, é uma proposta “... construída no diálogo e na contraposição a antigas práticas e concepções". (Silva, Pasuch \& Silva, 2012, p. 69).

Quando pensamos em educação infantil como direito social fundamental para as crianças camponesas, não estamos falando apenas de construir creches e préescolas com a proposta pedagógica desenvolvida no meio urbano. Significa assegurar uma educação infantil que contemple as especificidades do modo de vida camponesa e que não seja construído para, mas que seja construída com os camponeses e que seja ofertado perto ou na comunidade onde moram as crianças. $\mathrm{Ou}$ seja,

uma educação do campo, entendida como direito nos marcos da equidade, o que inclui a justiça social e o reconhecimento das 
especificidades, rejeita a imposição de um modelo educacional $\mathrm{e}$ pedagógico que nega as culturas e os saberes e os modos de produção da vida das populações do campo (Silva, Pasuch \& Silva, 2012, p. 59).

É possível afirmar, com certa tranquilidade, que a Constituição Federal de 1988 é um marco na história da Educação Infantil brasileira, sobretudo com o seu desdobramento na LDB $\mathrm{n}^{\circ}$ 9.394 de 1996 que a reconhece como primeira etapa da educação básica. Entretanto, durante muitos anos isso não passou de letra morta, ou seja, pouco foi feito para assegurar esse direito, sobretudo porque faltava recurso financeiro, pois essa etapa da educação básica não era obrigatória e ficava sob a responsabilidade dos municípios. De 1996 a 2006, com a implantação do Fundo de Manutenção e Desenvolvimento do Ensino Fundamental e de Valorização do Magistério FUNDEF, a educação infantil ficou à margem. A partir de 2007, com a Lei 11.494 de 20 de junho do referido ano, é que a situação começa a apresentar sinais de mudança com a criação do FUNDEB, haja vista que ele se destina à manutenção da Educação Básica e não apenas a uma etapa como era o caso do FUNDEF.

A educação infantil para os povos do campo começa a ser contemplada pelas políticas públicas de Estado a partir de
1998, em função da abertura encontrada na atual LDB, a qual traz a educação infantil como primeira etapa da educação básica, e no artigo 28 e assegura a especificidade da educação para os estudantes camponeses, somada à forte pressão exercida pelos segmentos sociais do campo.

O resultado deste tensionamento foi a publicação das Diretrizes Operacionais para Educação Básica das Escolas do Campo instituídas pela Resolução no 01 CNE/CEB de abril de 2002 e as Diretrizes Complementares instituídas por meio da Resolução $n^{\circ} 02$ CNE/CEB de abril de 2008. No que diz respeito à educação para os povos do campo, a Resolução $n^{\circ} 01$ CNE/CEB, de abril de 2002, traz no artigo $5^{\circ}$

as propostas pedagógicas das escolas do campo, respeitadas as diferenças e o direito a igualdade e cumprindo imediata e plenamente o estabelecido no artigo 23, 26 e 28 da lei 9394 de 1996, contemplarão a diversidade do campo em todos os seus aspectos sociais, culturais, políticos, de gênero e etnia (Brasil, 2002).

Destaca ainda no artigo $7^{\circ}$ que os sistemas de ensino podem organizar os tempos formativos respeitando o calendário agrícola.

Já a resolução CNE/CEB $n^{\circ} 2$, de 2008, destaca que a educação infantil no meio rural não pode ser ofertada na mesma sala do ensino fundamental, nos casos de classes multisseriadas. Diz também que 
quando houver nucleação das escolas do campo as unidades de educação infantil não podem ser inseridas nesse processo, haja vista que essas crianças não podem utilizar o transporte escolar, obrigando os municípios a manterem unidades de educação infantil nas comunidades onde residem as crianças.

O decreto 7.352, de 04 de novembro 2010, no artigo $4^{\circ}$, destaca que os entes federados em cooperação buscarão desenvolver ações que ampliem a oferta da educação básica no campo e assegura no inciso I a oferta da educação infantil em creches e pré-escolas como condição para possibilitar o desenvolvimento integral das crianças de 0 a 05 anos.

Temos ainda o Plano Nacional de Educação - PNE, instituído pela Lei $\mathrm{n}^{\circ}$ 10.172, de 09 de janeiro de 2001. Este apresentava um breve diagnóstico da educação infantil com dados cada vez mais tristes sobre a primeira etapa da educação básica. Trazia como meta, dentre tantas outras, "meta 01 ampliar a oferta da educação infantil de forma a atender, em cinco anos, $30 \%$ da população de até 03 anos de idade e $60 \%$ da população de 04 a 06 anos e, até o final da década alcançar a meta de $50 \%$ das crianças de 0 a 03 anos e 80\% das de 04e 06\%. (PNE 2001-2010).

No final da década que antecede esse plano, o Brasil vivenciava um momento singular no que se referia às discussões do campo, protagonizadas por um conjunto de sujeitos, dentre eles, as universidades, Conferência Nacional dos Bispos do Brasil - CNBB e segmentos sociais da educação. Foi uma década marcada por intensos debates em torno de conceitos importantes, como: campo, educação, educação do campo, sujeitos do campo articulando, sobretudo, em torno do Movimento Nacional por uma Educação do Campo, através do qual iniciou a construção do paradigma de campo e de educação do campo.

Apesar do contexto de debates em prol da educação do campo, especificamente a partir dos anos de 1988, estes não foram suficientes para pressionar o Estado a incluir um artigo sobre educação do campo no PNE 2001-2010, ou seja, o referido documento nem ao menos tangenciou nas questões da educação infantil para as crianças camponesas. As metas previstas para essa etapa da educação não fazem distinção entre as realidades urbana e rural.

$\mathrm{O}$ atual PNE foi gestado e publicado em um período marcado pelo tensionamento entre o estado e os segmentos sociais do campo e pelo protagonismo do Movimento Nacional por uma Educação do Campo, que resultou em duas conferências nacionais que 
aconteceram em 1998 e 2004, em Luziânia-GO. Pela primeira vez, esse plano fala da educação para os camponeses em todos os níveis da educação básica. No que se refere à educação infantil, traz na meta 01 "universalizar até 2016 a educação infantil na pré-escola para as crianças de 4 a 05 anos e ampliar a oferta da educação infantil em creches de forma a atender no mínimo, cinquenta por cento das crianças de até 03 anos até a vigência deste PNE". (PNE 2014-2024).

Para alcançar essa meta no que se refere à educação infantil no meio rural, a estratégia 1.10 diz o seguinte:

fomentar o atendimento das populações do campo e das comunidades indígenas $\mathrm{e}$ quilombolas na educação infantil nas respectivas comunidades, por meio do redimensionamento da distribuição territorial da oferta, limitando a nucleação de escolas e o deslocamento de crianças, de forma a atender as especificidades dessas comunidades, garantindo consulta prévia e informada (PNE 20142024).

Observamos que embora consideremos que o PNE avançou por trazer no seu bojo a Educação Básica do Campo, no que se refere à educação infantil para as crianças camponesas, ele não diz garantir ou assegurar, mas apenas fomentar o atendimento.

A pressão que os movimentos e demais segmentos do campo exerceram sobre o Estado influenciou a inclusão de pontos importantes sobre a educação básica do campo nos documentos e leis da educação, como a publicação de diretrizes específicas para essa modalidade de educação, além da instituição da política de educação do campo.

Em função desses enfrentamentos, as Diretrizes Curriculares Nacionais para a Educação Infantil, instituídas por meio da resolução $\mathrm{n}^{\circ}$ 05, de 17 de dezembro de 2009, já contemplam em seu texto as especificidades das crianças camponesas de 0 a 05 anos como também os elementos da produção e reprodução do modo de vida no campo. Esta resolução traz no artigo $4^{\circ}$ que as crianças são sujeitos históricos e de direitos, traz também no artigo $8^{\circ}$, parágrafo $3^{\circ}$, que

as propostas pedagógicas da educação infantil das crianças filhas de agricultores familiares, extrativistas, pescadores artesanais, ribeirinhos assentados e acampados de áreas de reforma agrária, quilombolas, caiçaras e povos da floresta devem:

I - reconhecer os modos próprios de vida no campo como fundamentais para a constituição da identidade das crianças moradoras em territórios rurais;

II - ter vinculação inerente à realidade dessas populações, suas culturas, tradições e identidades, assim como a práticas ambientalmente sustentáveis; 
III - flexibilizar, se necessário, calendário, rotinas e atividades respeitando as diferenças quanto à atividade econômica dessas populações;

IV - valorizar e evidenciar os saberes e o papel dessas populações na produção de conhecimentos sobre o mundo e sobre o ambiente natural;

$\mathrm{V}$ - prever a oferta de brinquedos e equipamentos que respeitem as características ambientais e socioculturais da comunidade (Brasil, 2009).

Essas diretrizes trazem contribuições importantes para ressignificar as práticas de educação infantil do campo, sobretudo porque ressalta a importância da educação dessas crianças pequenas e porque reconhece que as especificidades do modo de vida no campo são importantes na construção da identidade dessa criança, além da possibilidade de flexibilizar calendários e rotinas respeitando as especificidades da atividade econômica dos camponeses.

No que se refere à legislação, os avanços são significativos e facilmente identificados. As DCNEI são exemplo dessa evolução na história da educação infantil do campo. No entanto, na prática, a realidade dessa etapa da educação básica no campo ainda carece de empenho e investimento de recursos financeiros, materiais e humano para assegurar plenamente a condição de sujeitos de direito às crianças camponesas.
O PNE atual traz como meta universalizar a educação pré-escolar até 2016 e aumentar para $60 \%$ o atendimento em creches até o final da vigência do PNE. Merece ressaltar que ele não faz distinção entre educação infantil urbana e rural quando trata dessa meta (meta 01). Ao analisar o censo do INEP (2015) é possível perceber que essa meta ainda está muito longe de ser alcançada. Segundo esse censo, temos um total de 1.925.644 crianças com até 03 anos matriculadas em creches e 3.651 .786 crianças com 04 e 05 anos matriculadas na pré-escola. Do total de crianças matriculadas nas creches, aproximadamente $91 \%$ estão no meio urbano e $8,87 \%$ estão no meio rural. No que se refere à pré-escola, $81 \%$ estão matriculadas no meio urbano e apenas 18,3 estão matriculadas no meio rural.

Apesar do empenho dos entes federados, a meta ainda está longe de ser alcançada. Em se tratando da educação infantil do campo, essa realidade é ainda mais complicada e demanda um número de esforços infinitamente superior para que a meta seja alcançada. Esses dados ilustram que ainda existe uma injusta concentração de investimentos na educação infantil urbana e evidenciam que existe uma significativa diferença na priorização de investimentos nessa etapa da educação básica, concentrando-os no meio urbano. 
Conforme o relatório síntese da Pesquisa Nacional Caracterização das práticas educativas com crianças de 0 a 6 anos de idade residente em área rural (2012), a educação infantil constitui uma resposta às demandas decorrentes do processo de industrialização e urbanização. A priorização em atender às demandas decorrentes do processo do desenvolvimento industrial, pode ser uma das possíveis explicações para a pouca oferta da educação infantil para as crianças camponesas. Além disso, destaca a invisibilidade das crianças camponesas menores de 06 anos.

Em decorrência dessa situação, muitas crianças precisam deslocar de suas comunidades em barcos, no caso de ribeirinhos e ilhéus, ou de carro nos demais casos, para terem acesso à escolarização na cidade. Ou seja, a concentração das matrículas nas creches e pré-escolas no meio urbano demonstra a história de negação de direitos que os camponeses e suas crianças têm vivenciado.

A Pesquisa Nacional de Amostra por Domicílios-PNAD (2014, p. 45) registrou que "o maior aumento da taxa de escolarização deu-se na faixa das crianças de 04 e 05 anos de idade, 82,7\% em 2014, frente a 81,4\% em 2013". Apesar de ter havido um crescimento no número de matrículas, ainda assim, a quantidade de crianças pequenas no campo esperando por uma oportunidade de frequentar a educação infantil é expressiva.

No campo da legislação a educação infantil goza de um espaço crescente, entretanto, na prática, a educação das crianças menores de 05 anos tem contado com um investimento, particularmente financeiro, muito aquém das demandas dessa etapa da educação básica. A realidade das unidades de ensino, na maioria dos municípios, não atende ao que propõe o documento intitulado "Parâmetros Básicos de Infraestrutura para Instituições de Educação Infantil 2006". A realidade para as crianças camponesas de 0 a 5 anos ainda é marcada pela omissão e ausência dos governos.

Ainda temos um expressivo número de crianças com menos de seis anos fora da escola e mais de $80 \%$ das crianças de 0 a 03 anos não têm espaço para estudar. Temos ainda a realidade de crianças que frequentam inadequados pedagogicamente, ou seja, estudam em salas improvisadas sem espaço adequado, sem os recursos necessários como, por exemplo, local para o sono de descanso das crianças, que, aliás, é essencial para aquelas pequenas crianças que precisam deslocar através do transporte escolar para chegar à unidade ou sala de educação 
infantil que estão longe de sua comunidade.

São raras as comunidades rurais que possuem unidades de educação infantil. A maioria das comunidades não possuem creches para atender as crianças de 0 a 03 anos e para as crianças de 04 e 05 anos. Em geral, há apenas uma sala em uma escola de ensino fundamental, sem ambiência adequada, com uma organização mais próxima do ensino fundamental, inclusive com mesas, cadeiras, banheiros adaptados à realidade de crianças de 07 anos ou mais.

\begin{abstract}
A história internacional tem mostrado que não tem escapado à lógica de produção e reprodução da pobreza via políticas públicas: as crianças mais pobres, de área rural, mesmo em países desenvolvidos, tendem, via de regra, a frequentar instituições de educação infantil de pior qualidade que as crianças não pobres e de áreas urbanas (Barbosa et al., 2012, p. 19)
\end{abstract}

A partir do ano 2000, o campo brasileiro tem vivido a realidade das nucleações das escolas, na qual as crianças são deslocadas a contragosto para escolas em outras comunidades ou para o meio urbano, e, consequentemente, o fechamento das escolas unidocentes no campo. No período de 2000 a 2015, foram fechadas 37 mil escolas do campo. Só em 2014 fecharam 4084 escolas. Sobre nucleações, a Resolução CNE/CEB no 02 , de 28 de abril de 2008, destaca que estas só devem ser feitas intracampo e exclui a educação infantil desse processo.

Para atender o disposto na Lei $\mathrm{n}^{\circ}$ 12.796, de 04 de abril de 2013, que tornou obrigatório o estudo dos 04 aos 17 anos, e com a demanda do atual o PNE de universalizar as matrículas das crianças de 04 e 05 anos, muitos municípios passaram a disponibilizar apenas uma sala em escolas do ensino fundamental para atender esse universo de crianças. Silva, Pasuch e Silva (2012) destacam que as crianças do campo são as que têm o acesso à educação infantil dificultado. Ressaltam ainda que estudos evidenciam que, quando ofertam a educação infantil, geralmente é longe de suas residências e em condições bastante precárias.

Analisando o contexto da educação infantil para as crianças camponesas, percebe-se que na legislação essa etapa da educação básica já está contemplada enquanto direito social fundamental. No entanto, na prática esse direito está longe de se concretizar de fato, haja vista que tem apenas assegurado à matrícula e não tem garantido as condições para possibilitar um padrão mínimo de qualidade. Ou seja, o atendimento às demandas das crianças de 0 a 5 anos, particularmente as que residem no campo, foi e está sendo marcado pelo 
tensionamento entre uma legislação que assegura o dever do Estado em garantir os direitos das crianças e o contexto de desigualdades no acesso aos recursos econômicos e culturais, dificultando o reconhecimento da cidadania dessas crianças.

\section{Considerações finais}

O campo e a Educação do Campo, a partir de 1998, passaram por um processo de ressignificação. Os sujeitos que moram nesse espaço, particularmente aqueles que se encontram organizados em movimentos sociais, conquistaram ainda que, mais no papel que na prática, a posição de protagonistas. Desse modo, as ações, as políticas e as proposições para a Educação do Campo precisam ser construídas com esses sujeitos e não para eles, como propõe as Diretrizes Operacionais para a Educação Básica das escolas do Campo no seu artigo 10

o projeto institucional das escolas do campo, considerando o estabelecido garantirá gestão democrática, constituindo mecanismos que possibilitem estabelecer relações entre escola, comunidade local, os movimentos sociais, os órgãos normativos do sistema de ensino e os demais setores da sociedade (Brasil, 2002).

As discussões sobre educação para os sujeitos do campo concentraram particularmente no ensino fundamental. A educação infantil para as crianças camponesas não goza da mesma atenção. Entretanto, em decorrência dos enfrentamentos entre segmentos sociais ligados à luta pela terra e o Estado, sobretudo, no que se refere ao papel deste para assegurar a educação como direito de todos, a educação infantil do campo foi sendo contemplada nos documentos que orientam a organização dos sistemas de ensino, particularmente, na atual DCENEI.

É possível afirmar que a partir de 1998 até os dias atuais a educação infantil conseguiu avanços significativos em termos de leis. No entanto, muito ainda precisa ser feito para que ela seja universalizada para atender as crianças de 0 a 03 anos e de 4 e 5 anos no meio rural, pois ainda deparamos com um número expressivo de crianças camponesas sem a oportunidade de frequentar creches e préescolas.

As crianças que conseguem vagas na educação infantil do campo vivenciam condições extremamente precárias e a maioria dessas crianças precisam se deslocar de suas comunidades em busca de espaço que as atendam, o que contraria o artigo $3^{\circ}$ da Resolução CNE/CEB nº 02, de abril de 2008, que institui as Diretrizes complementares.

Por fim, as lutas precisam continuar para que as proposições legais tornem 
ações concretas, potencializando $\mathrm{o}$ movimento rumo à universalização da educação infantil no campo, assegurada em condições adequadas para que alcance a qualidade esperada pela sociedade articulada com os princípios da Educação do Campo presentes no Decreto 7352, de 04 de novembro de 2010. Esse movimento é necessário para que a educação infantil destinada às crianças do campo seja plenamente garantida enquanto direito humano social fundamental.

\section{Referências}

Andrade, L. B. P. (2010). Educação infantil: discurso, legislação e práticas institucionais [online]. São Paulo: Editora UNESP/São Paulo: Cultura Acadêmica.

Arroyo, M. G. (1982). Escola, Cidadania e Participação no Campo. Em Aberto, 1(9), 1-6.

Brasil. (1891). Constituição da República dos Estados Unidos do Brasil de 24 de fevereiro de 1891. Recuperado em 17 de julho de 2015 de http://www.planalto.gov.br

Brasil. (1934). Constituição da República dos Estados Unidos do Brasil de 16 de julho de 1934. Recuperado em 17 de julho de 2015 de http://www.planalto.gov.br

Brasil. (1946). Constituição da República dos Estados Unidos do Brasil de 18 de setembro de 1946. Recuperado em 17 de julho de 2015 de http://www.planalto.gov.br/

Brasil. (1988). Constituição da República Federativa do Brasil de 1988. Recuperado
17 de julho de 2015 http://www.planalto.gov.br/

Barbosa, M. C. S. et al. (Orgs.). (2012). Oferta e demanda da educação infantil no campo. Porto Alegre: Evangraf.

Bobbio, N. (2004). A Era dos Direitos. Rio de janeiro: Elsevier.

Cavalcante, L. O. H. (2010). Das políticas ao cotidiano: entraves e possibilidades para a educação do campo alcançar as escolas no rural. Ensaio: aval. pol. públ. Educ., 18(68), 549-564.

Comparato, F. K. (2010). A Afirmação Histórica dos Direitos Humanos. São Paulo: Editora Saraiva.

Decreto Lei $\mathrm{n}^{\mathrm{o}} 5452$ de $1^{\circ}$ de maio de 1943. (1943). Aprova a Consolidação das Leis do Trabalho. Presidência da Casa Civil. Brasília. Recuperada em 15 de agosto de 2016 de http://www.planalto.gov.br

Decreto 7352 de 04 de novembro 2010. (2010). Dispõe sobre a política de educação do campo e o Programa Nacional de Educação na Reforma Agrária - PRONERA. Ministério da Educação. Brasília: MEC. Recuperado em Disponível 12 de março de 2003 de http://www.planalto.gov.br

Fernandes, B. M. (2006). Os Campos da Pesquisa em Educação do Campo: espaço e territórios como categorias essenciais. In Molina, M. C. (Org.). Educação do Campo e Pesquisa: questões para reflexão. Brasília: MDA.

IBGE. Populações nos sensos demográficos, segundo as grandes regiões, as unidades da federação e a situação do domicílio-1960-2010. Recuperado em 15 de setembro de 2016 de http://www.censo2010.ibge.gov.br/sinopse. 
INEP. Censo escolar 2015. Recuperado em 15 de setembro de 2016 de http://portal.inep.gov.br/basica-censo

Kuhlmann Jr. (2000). M. Histórias da Educação Infantil Brasileira. Revista Brasileira de Educação, (14), 5-18.

Lei $\mathrm{n}^{\circ} 9394$ de 20 de Dezembro de 1996. (1996). Estabelece as diretrizes e bases para a Educação Nacional. Ministério da Educação. Brasília: MEC. Recuperada em 17 de julho de 2015 de http://www.planalto.gov.br/

Lei $\mathrm{n}^{\circ} 10.172$ de 09 de janeiro de 2001. (2001). Aprova o Plano Nacional de Educação e dá Outras Providências. Ministério da Educação. Brasil. MEC. Recuperado em 10 de agosto de 2015 de http://www.planalto.gov.br

Lei ${ }^{\circ} 13005$ de 25 de junho de 2014. (2014). Aprova o Plano Nacional de Educação e da outras providências. Brasília: Câmara dos Deputados, Edição Câmara.

Lei $\mathrm{n}^{\circ} 5.692$ de 11 de agosto de 1971. (1971). Fixa as Diretrizes e Bases para o ensino de $1^{o}$ e $2^{o}$ Graus e da Outras Providências. Brasília. Recuperado em 15 de agosto de 2016 de http://www.planalto.gov.br/. Acessado em 13 de set de 2015.

Lei $\mathrm{n}^{\circ}$ 12.796, de 4 de abril de 2013. (2013). Altera a Lei no 9.394, de 20 de dezembro de 1996, que estabelece as diretrizes e bases da educação nacional, para dispor sobre a formação dos profissionais da educação e dar outras providências. Presidência da Casa Civil. Brasília. Recuperado 15 de agosto de 2016 de http://www.planalto.gov.br

Lei $\mathrm{n}^{\circ} 4024$ de 20 de dezembro de 1961. (1961). Fixa as Diretrizes e Bases da Educação Nacional. Recuperado em 13 de set de 2015 de http://wwwp.fc.unesp.br
Parâmetros básicos de infraestrutura para instituições de educação infantil. (2006). Ministério da Educação. Secretaria de Educação Básica. Brasília: MEC, SEB.

Pesquisa Nacional Caracterização das práticas educativas com crianças de 0 a 6 anos de idade residentes em área rural 2012. (2012). Relatório Síntese. MEC/CEB/UFRGS.

Pesquisa Nacional por Amostra de Domicílios: síntese de indicadores 2014 / IBGE. (2015). Coordenação de Trabalho e Rendimento. Rio de Janeiro: IBGE.

Resolução $\mathrm{n}^{\circ} 02$ de 28 de abril de 2008. (2008). Estabelece as diretrizes complementares, normas e princípios para o desenvolvimento de políticas públicas de atendimento da Educação Básica do Campo. Ministério da Educação. Conselho Nacional de Educação. Brasília: MEC/CNE Recuperado em 15 de abril de 2015 de http://portal.mec.gov.br

Resolução CNE/CEB n ${ }^{\circ} 1$ de 3 de abril de 2002. (2002). Estabelece Diretrizes Operacionais para a Educação Básica nas Escolas do Campo. Ministério da Educação. Conselho Nacional de Educação. Brasília: MEC/CNE.

Resolução MEC/CNE/CEB n ${ }^{\circ}$ 5, de 17 de dezembro de 2009. (2009). Fixa as Diretrizes Curriculares Nacionais para a Educação Infantil. Ministério da Educação. Conselho Nacional de Educação. Câmara de Educação Básica. Brasília: MEC/CNE/CEB.

Silva, A. P. S., Pasuch, J., \& Silva, J. B. (2012). Educação Infantil do Campo. São Paulo: Cortez.

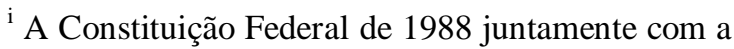
LDB n ${ }^{\circ} 9394$ de 1996 estabeleciam o Ensino Fundamental com duração de oito anos e a Educação Infantil compreendia a idade de 0 a 06.
} 
Entretanto, a Lei $\mathrm{n}^{\circ} 11274$ de 06 de fevereiro de 2006 alterou a LDB e estabeleceu a duração de 09 anos para o Ensino Fundamental, etapa de estudo na qual as crianças iniciarão aos 06 anos. Desse modo, a educação Infantil passou a compreender a idade de 0 a 05 anos.

Recebido em: 10/10/2016

Aprovado em: 26/11/2016

Publicado em: 19/04/2017

Como citar este artigo / How to cite this article / Como citar este artículo:

APA:

Moreira, E. S., Rosa, G. M., \& Oliveira, I. F. (2017). Educação infantil no campo e os avanços no aspecto legal: reconhecimento da educação como direito social para as crianças camponesas. Rev. Bras. Educ. Camp., 2(1), 163-183. DOI: http://dx.doi.org/10.20873/uft.2525-

$\underline{4863.2017 \mathrm{v} 2 \mathrm{n} 1 \mathrm{p} 163}$

ABNT:

MOREIRA, E. S.; ROSA, G. M.; OLIVEIRA, I. F. Educação infantil no campo e os avanços no aspecto legal: reconhecimento da educação como direito social para as crianças camponesas. Rev. Bras. Educ. Camp., Tocantinópolis, v. 2, n. 1, p. 163-183, 2017. DOI: http://dx.doi.org/10.20873/uft.2525$\underline{4863.2017 \mathrm{v} 2 \mathrm{n} 1 \mathrm{p} 163}$ 